\title{
The use of nanotechnology as a tool to control environmental pollution: An overview
}

\author{
Arshad Husain ${ }^{1 *}$ and Iram Javed ${ }^{2}$ \\ ${ }^{1}$ Civil Engg. Section, F/O Engg. \& Technology, AMU, Aligarh (U.P.) India \\ ${ }^{2}$ Civil Engg. Deptt., ZHCET, AMU, Aligarh(U.P.)India \\ *Email: ahusainamu@yahoo.co.in
}

Increased industrialisation has resulted in broad energy consumption and climatic changes due to the emission of greenhouse gases. To tackle the problem of air pollution such innovative technologies are required that can provide socially acceptable solutions through energy savings; efficiency gains; and decarbonisation. The researchers around the world have demonstrated the potential for nanotechnology to be a key technology on the path to a sustainable energy future. Nanotechnology is the engineering of functional systems conducted at the nano scale. There is a fast growth in the field of nanotechnology during the last 20 years. This paper presents an overview of nanotechnology applications in the field of environmental engineering such as water and wastewater treatment with specific focus on remediation for the removal of micropollutants.

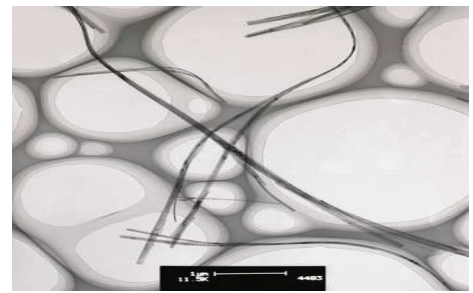

Figure 1: Transmission electron microscopy image of the titanate nanofibers

Nanotechnology works for environmental improvement, for the production of efficient and cost effective energy, reduction of pollution during the manufacture of materials. Similarly, the nanomaterials that contain the particle size less than $100 \mathrm{~nm}$ in at least one dimension are very important product of nanotechnology. Nanomaterials are coming into use in electronics, health care cosmetics etc. The environment can be improved by nanotechnology through the direct application of nanomaterials to prevent, detect and remove pollutants from it as well as by using cleaner industrial processes and environment friendly products made by nanotechnology for example iron nanoparticles can remove contaminants from soil and groundwater. Membranes of titanate nanofibers (Figure 1), carbon nanotube (Figure 2), etc. can be used for the desalinisation of seawater. Nanofiltration techniques can also be used for indoor air purification. The use of nanofilter in factory smokestacks and tail pipes of automobiles to filter the contaminants and prevent them from entering the environment is also becoming popular. The potential impact areas for nanotechnology in water applications are divided into three categories, i.e. treatment and remediation, sensing and detection and pollution prevention. Prof. Eugene Cloete has worked in the field of nanotechnology that has contributed to long term water quality, availability and viability of water resources through the use of advanced filtration materials that enable greater water reuse, recycling and desalinization $[1,2\}$.

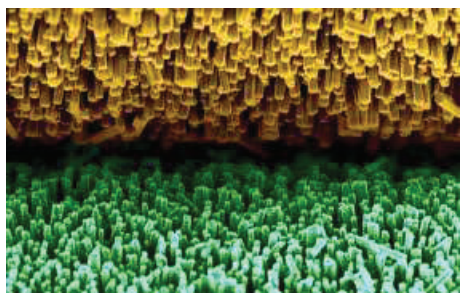

Figure 2: Carbon Nanotubes

In advanced water purification and desalination, membranes are considered as key component. Researchers have found that conventional technologies like solvent extraction, activated carbon adsorption and chemical oxidation are very costly and time consuming. Nanotechnology has an important role in the remediation of contaminated water, which includes the processes of removal, reduction or neutralisation of water contaminants that are posing a potential threat to humans, plants and animals. Moreover, there are many micropollutants present today in surface water and ground water. Some of these micropollutants are insecticides and pesticides such as DDT, Lindane, Chlordane, Mirex, Toxaphene etc. Heavy metals such as Nickel, Chromium, Zinc, lead etc are also a big problem. Nanotechnology provides a better environmental solution for the removal of such micropollutants.

\section{References}

1. Theron, J.; J. A. Walker; T. E. Cloete, "Nanotechnology and Water Treatment: Applications and Emerging Opportunities". Critical Reviews in Microbiology, 34 (1): 43-69, 2006.

2. U.S. EPA (2012-11-14). "Nanotechnologies for environmental cleanup" ,2014. 